Summary: The poly(amidoamine)s (PAAs) ISA 1 and ISA 23 display $\mathrm{pH}$-dependent conformational change and $\mathrm{pH}$ dependent membrane perturbation. These properties confer potential for use as endosomolytic polymers for intracytoplasmic delivery of toxins and genes. Both polymers are relatively non-toxic, and moreover ISA 23 has the beneficial property in vivo, of being non hepatotropic when administered intravenously. Although ISA 23 and ISA 1 demonstrate ability to transfect cells, ISA 1 is also able to promote intracellular delivery of non-permeant toxins. The aim of this study was to synthesise random and block copolymers of ISA 1 and ISA 23 and investigate whether these second generation hybrids would allow optimisation of PAA biological characteristics. Random and block copolymers of ISA 1 and ISA 23 were synthesised by hydrogen transfer polyaddition to generate a library of PAAs with an ISA 23:ISA 1 molar ratios of $2: 1$ to $4: 1$. The resultant polymers have a pI slightly below 7.4 and a $\bar{M}_{\mathrm{w}}$ of $19900-49000 \mathrm{~g} / \mathrm{mol}$ and a $\bar{M}_{\mathrm{n}}$ of $13100-24100 \mathrm{~g} / \mathrm{mol}$. Whereas none of the random or block copolymers were haemolytic at $\mathrm{pH} 7.4$ all demonstrated pH-dependent membrane activity. At pH 5.5 they caused 50$60 \%$ haemoglobin $(\mathrm{Hb})$ release over $1 \mathrm{~h}$. This was slightly less than that seen for ISA $23(80 \% \mathrm{Hb}$ release). None of the copolymers were cytotoxic against B $16 \mathrm{~F} 10$ cells during a $72 \mathrm{~h}$ incubation $\left(\mathrm{IC}_{50}>2 \mathrm{mg} / \mathrm{ml}\right.$; MTT assay). The ability of the random and block copolymer PAAs to deliver the toxin gelonin was also examined, but only ISA 1 and the block copolymer B2 (ISA 23:ISA 1 at a 2:1 molar ratio) were able to promote intracellular delivery, as measured by cytotoxic activity. It would be interesting to study the body distribution of B2 and determine whether this toxin-delivering PAA is able to escape liver capture.

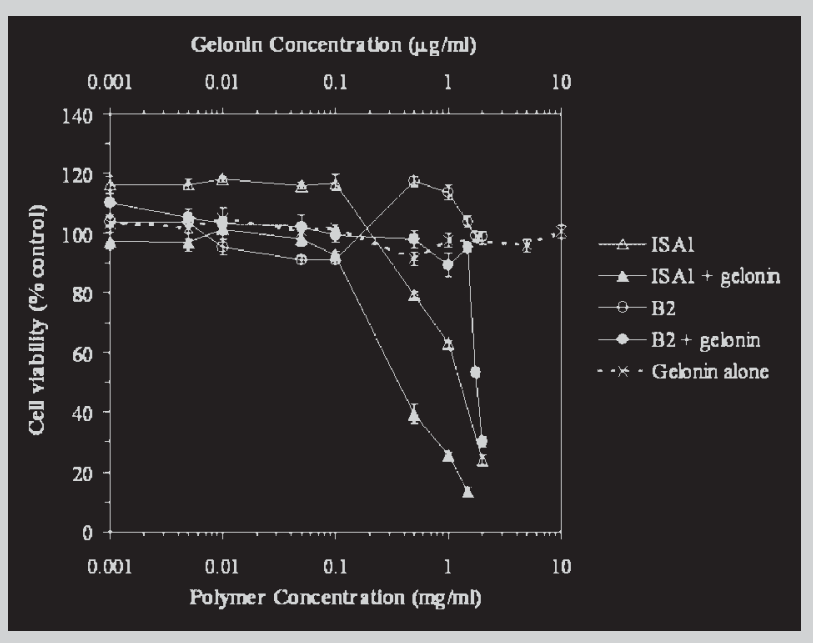

\title{
Synthesis and Endosomolytic Properties of Poly(amidoamine) Block Copolymers
}

\author{
Nathalie Lavignac, ${ }^{1}$ Michelle Lazenby, ${ }^{1}$ Peli Foka, ${ }^{1}$ Beatrice Malgesini, ${ }^{2}$ Ilario Verpilio, ${ }^{2}$ Paolo Ferruti, ${ }^{2}$ Ruth Duncan $* 1$ \\ ${ }^{1}$ Centre for Polymer Therapeutics, Welsh School of Pharmacy, Redwood Building, Cardiff University, King Edward VII Avenue, \\ Cardiff, CF10 3XF, UK \\ Fax: +44 (0)2920 874 536; E-mail: DuncanR@cf.ac.uk \\ ${ }^{2}$ Dipartimento di Chimica Organica e Industriale and Centro Interdisciplinare Materiali Innovativi Nanostrutturati (CIMAINA), \\ Università di Milano, Via Venezian 21, 20133, Milano, Italy
}

Received: June 30, 2004; Revised: August 6, 2004; Accepted: August 10, 2004; DOI: 10.1002/mabi.200400093

Keywords: block copolymers; endosomotropic delivery; pH-sensitive polymers; poly(amidoamine)s; random copolymers

\section{Introduction}

Poly(amidoamine)s (PAAs) are synthetic tert-amino polymers, which are produced by hydrogen transfer polyaddition of primary or secondary mono(amine)s to bis(acrylamide)s. ${ }^{[1-3]}$ They are water-soluble, biodegradable and are less toxic ${ }^{[4,5]}$ than other cationic polymers such as poly(L-lysine) ${ }^{[6]}$ polyethyleneimine $(\mathrm{PEI})^{[7]}$ or poly (amidoamine) (PAMAM) dendrimers ${ }^{[8]}$ all of which have been widely proposed as non-viral vectors. In aqueous solution, amino and amido groups arranged along the PAA polymeric chain confer moderate basicity to the polymer. ${ }^{[9]}$ As a result the polymer undergoes a conformational change from a relatively coiled (hydrophobic) to an open (hydrophilic) structure, when moved from a neutral to an acidic environment. This was confirmed by a pH-dependent haemolysis assay ${ }^{[9,10]}$ and more recently by small angle neutron scattering (SANS). ${ }^{[11,12]}$ In the context of 
promotion of intracellular delivery of macromolecular drugs, this property of PAAs has been used to mediate gene and non-permeant toxin delivery to the cytoplasm of the cell. $^{[13,14]}$

From the large library of PAAs so far examined, ${ }^{[4,9,10]}$ two PAAs have emerged as particularly interesting. The amphoteric ISA 23 (and its analogue ISA 22, in which $4 \%$ of 2-methylpiperazine units have been replaced by 2-(4hydroxy)phenylethylamine units to allow radioiodination) and the more cationic ISA 1 (and its 2-(4-hydroxy)phenylethylamine analogue, called ISA 4) (Figure 1). ${ }^{[10]}$ In vivo pharmacokinetic studies showed that ${ }^{125}$ I-labelled ISA 22 exhibited "stealth properties", i.e. it did not accumulate in the liver after intravenous injection. This polymer exhibits a prolonged blood circulation time ${ }^{[10]}$ that promotes tumour accumulation of ${ }^{125}$ I-labelled ISA 22 in mice bearing subcutaneous B16F10 melanoma. This is due to the enhanced vascular permeability of angiogenic blood vessels, leading to the passive targeting phenomenon called the enhanced permeability retention (EPR) effect. ${ }^{[15]}$ This makes ISA 23/ 22 particularly suitable for parenteral use.

In contrast, the in vivo pharmacokinetic profile of ${ }^{125} \mathrm{I}$ labelled-ISA 4 is less favourable as this PAA is cationic at physiological $\mathrm{pH}$ and consequently localises in the liver after intravenous injection, i.e. it is hepatotropic. ${ }^{[10]}$ Never the less ISA 1 displays one important advantage, as this PAA is able to promote cytosolic delivery of non-permeant toxins such as ricin A chain and gelonin. ${ }^{[14]}$

The aim of this study was to synthesise random and block copolymers of ISA 23 and ISA 1, and thus produce second generation hybrids that could combine the beneficial properties of the parent polymers - the enhanced cytosolic delivery of proteins of ISA 1, and stealth property of ISA 23.
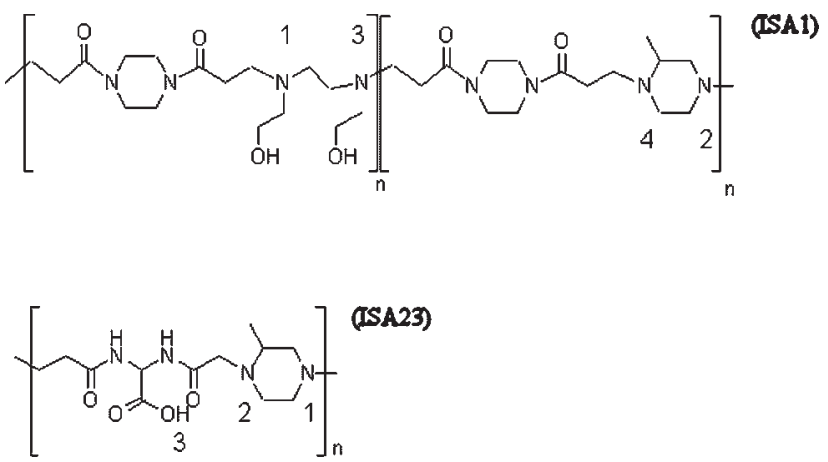

\begin{tabular}{ccccc}
\hline Polymer & $\mathrm{pKa} 1$ & $\mathrm{pKa} 2$ & $\mathrm{pKa} 3$ & $\mathrm{pKa} 4$ \\
\hline ISA1 & 8.1 & 6.9 & 3.8 & 3.0 \\
ISA23 & 7.5 & 3.25 & 2.1 & \\
\hline pKa values are from ref [9] and [14]
\end{tabular}

Figure 1. Structure of poly(aminoamide)s ISA 1 and ISA 23.
A library of ISA 23:ISA 1 random and block copolymers were synthesised having a molar ratio of $2: 1$ to $4: 1$. In the case of the block copolymers, it was first necessary to synthesise ISA 1 and ISA 23 with excess amine functionality so they could be used as macromonomers. ${ }^{[16]}$ To determine their structure activity relationships, the $\mathrm{pH}$ dependent haemolytic activity of each polymer was assessed using a rat red blood cell lysis assay, and cytotoxicity towards B16F10 murine melanoma was assessed by MTT assay. ${ }^{[17]}$ Gelonin was used as a model toxin to assess the in vitro ability of these PAAs to mediate intracellular delivery of proteins. ${ }^{[14]}$

\section{Materials and Methods}

\section{Instruments}

${ }^{1} \mathrm{H}-\mathrm{NMR}$ spectra were run in deuterated water on a Bruker $400 \mathrm{MHz}$ instrument. SEC chromatograms were obtained by using a waters 515 HPLC pump, with Toso-Haas 486 columns, using Tris buffer pH $8.00 \pm 0.05$ as mobile phase. Conditions: sample concentration $10 \mathrm{mg} / \mathrm{ml}$; flow rate $1 \mathrm{ml} /$ min; detector UV Knauer model, wavelength $230 \mathrm{~nm}$; temperature $30^{\circ} \mathrm{C}$, poly $(N$-vinylpyrrolidone) (PVP) fractions were used as reference standards.

\section{Materials}

Sodium hydrogen carbonate $\left(\mathrm{NaHCO}_{3}\right)$, concentrated $\mathrm{HCl}$ and hydroxyethylethylenediamine (DHE) were purchased from Fluka (Dorset, UK) and used without any purification. 2-Methylpiperazine (2-MePip) was also obtained from Fluka but was recrystallised from hexane, its purity was determined titrimetrically before use. 2,2-Bis(acrylamido)acetic acid (BAC) and bisacryloylpiperazine (PB) were synthesised as previously described, ${ }^{[18,19]}$ and their purity was determined titrimetrically (BAC) or by NMR (BP) just before use.

Dextran $\left(\bar{M}_{\mathrm{w}}=74000 \mathrm{~g} / \mathrm{mol}\right)$, gelonin, optical grade dimethyl sulfoxide (DMSO), 5-dimethylthiazol-2-yl-2,5diphenyltetrazolium bromide (MTT) and Triton X-100 were all from Sigma (Dorset, U.K) and were of analytical grade. PBS was supplied from Oxoid Ltd. (Basingstoke, U.K). RPMI 1640 medium supplemented with L-glutamine, foetal bovine serum (FBS) and $0.25 \%$ trypsin-EDTA were purchased from Gibco-BRL (Paisley, U.K). The B16F10 mouse melanoma cells were from ATCC (CRL-6475).

\section{Synthesis of Random Copolymers}

As a typical example, the synthesis of the random copolymer R2 is briefly described. A mixture of BAC $(3.0 \mathrm{~g}, 15.13 \mathrm{mmol})$, sodium hydrogen carbonate $(1.272 \mathrm{~g}$, $15.13 \mathrm{mmol})$ and water $(7.5 \mathrm{ml})$ was stirred until a clear 
solution was obtained. The solution was flushed with nitrogen, then BP (1.47 g, $7.56 \mathrm{mmol}), 2-\mathrm{MePip}$ (96.5\% purity, $1.96 \mathrm{~g}, 18.9 \mathrm{mmol}$ ) and DHE (95\% purity, $0.59 \mathrm{~g}$, $3.78 \mathrm{mmol}$ ) were added and the resultant mixture maintained $3 \mathrm{~d}$ at room temperature under a nitrogen atmosphere. After this time the mixture was diluted with one volume water and $37 \%$ hydrochloric acid added until the $\mathrm{pH}$ was reduced to 2.5. After further dilution the product was ultrafiltered through a membrane with nominal cut-off $10000 \mathrm{Da}$. The portion retained by the membrane was finally recovered by liophylisation. The yield was about $70 \%$ of the theoretical.

The same procedure was followed to synthesised R3 and $\mathrm{R} 4$ using the ratio of reactants as shown below:

R3: BAC $3.0 \mathrm{~g}$ (15.13 mmol); sodium hydrogen carbonate $1.272 \mathrm{~g}(15.13 \mathrm{mmol})$; water $6.7 \mathrm{ml}$; BP $0.98 \mathrm{~g}$ (5.043 mmol); 2-MePip $1.83 \mathrm{~g}$ (17.65 mmol); DHE $0.39 \mathrm{~g}$ ( $2.63 \mathrm{mmol})$.

R4: BAC $3.0 \mathrm{~g}(15.13 \mathrm{mmol})$; sodium hydrogen carbonate $1.272 \mathrm{~g}(15.13 \mathrm{mmol})$; water $6.3 \mathrm{ml}$; BP $0.734 \mathrm{~g}$ (3.78 mmol); 2-MePip $1.766 \mathrm{~g}(17 \mathrm{mmol})$; DHE $0.29 \mathrm{~g}$ (1.89 mmol).

The yields were the same in each case.

\section{Synthesis of Block Copolymers}

As a typical example, the synthesis of the block copolymer B2 is described below. First, the $\alpha, \omega$-bisamino terminated ISA1 pre-polymer was prepared. A mixture of BP $(1.47 \mathrm{~g}$, $756.5 \mu \mathrm{mol})$, water $(2.52 \mathrm{ml}), 2-\mathrm{MePip}$ (96.5\% purity, $0.4122 \mathrm{~g}, 8.32 \mathrm{mmol}$ ) and DHE (95\% purity, $0.62 \mathrm{~g}$, $8.32 \mathrm{mmol}$ ) was stirred until a clear solution was obtained. The resultant mixture was maintained $3 \mathrm{~d}$ at room temperature under a nitrogen atmosphere. This intermediate was used without further purification.

To prepare the $\alpha, \omega$-bisamino terminated ISA23 prepolymer, a mixture of BAC $(3.0 \mathrm{~g}, 15.13 \mathrm{mmol})$, sodium hydrogen carbonate $(1.272 \mathrm{~g}, 15.13 \mathrm{mmol})$; water $(5.04 \mathrm{ml})$ and 2-MePip (96.5\% purity, $1.727 \mathrm{~g}, 16.6 \mathrm{mmol}$ ) was stirred until a clear solution was obtained. The resultant mixture was also maintained $3 \mathrm{~d}$ at room temperature under a nitrogen atmosphere, and used without further purification.

The third component, a 1:1 mixture of $\mathrm{BAC} / \mathrm{BP}$ was prepared as follows. A mixture of BAC $(0.3 \mathrm{~g}, 1.513 \mathrm{mmol})$, BP $(0.147 \mathrm{~g}, 757 \mu \mathrm{mol})$ and sodium hydrogen carbonate $(0.127 \mathrm{~g}, 1.513 \mathrm{mmol})$ and water $(2 \mathrm{ml})$ was stirred until homogeneous and then flushed with nitrogen in order to eliminate the resultant carbon dioxide.

Finally, to synthesise the block copolymer B2, the $\alpha, \omega-$ bisamino terminated ISA1 pre-polymer, the $\alpha, \omega$-bisamino terminated ISA23 pre-polymer and the 1:1 $\mathrm{BAC} / \mathrm{BP}$ described above were thoroughly mixed in a flask and left for $2 \mathrm{~d}$ at room temperature. After this time the mixture was diluted with one volume water, treated with $37 \%$ hydrochloric acid until $\mathrm{pH} 2.5$, and after further dilution ultrafiltered through a membrane with nominal cut-off $10000 \mathrm{Da}$. The portion retained by the membrane was finally recovered by liophylisation. The yield was about $70 \%$ of the theoretical.

The block copolymers B3 and B4, were prepared using the same procedure. Whilst the quantities of $\alpha, \omega$-bisamino terminated ISA23 pre-polymer and 1:1 mixture of BAC/BP remained the same, the monomer feed ratio for the synthesis of $\alpha, \omega$-bisamino terminated ISA1 pre-polymer changed as follow:

B3: BP (0.98 g, $5.1 \mathrm{mmol})$, water (1.68 ml), 2-MePip (0.275 g, $2.7 \mathrm{mmol})$, DHE (0.413 g, $2.7 \mathrm{mmol})$.

B4: BP (0.735 g, $3.78 \mathrm{mmol})$, water (1.26 ml), 2-MePip (0.206 g, $2.06 \mathrm{mmol})$, DHE (0.31 g, $2.06 \mathrm{mmol})$.

\section{NMR Characterisation of the Copolymers}

The ${ }^{1} \mathrm{H}$ NMR $\left(\mathrm{D}_{2} \mathrm{O}\right)$ spectrum of ISA1 was as follows: $\mathrm{CH}_{3}$ of 2-MePip 1.3 ppm d; $\mathrm{CH}_{2}$ of 2-MePip 3.1-3.8 ppm m (complex system); $\mathrm{CH}_{2}$ in $\alpha$ and $\beta$ to the amidic group of $\mathrm{BP}$ 3.2-4.0 ppm m (complex system); $\mathrm{CH}_{2}$ of the ring of $\mathrm{BP}$ 3.1-3.8 ppm m (complex system); $\mathrm{CH}_{2}$ in $\alpha$ to the nitrogen groups of DHE $2.7 \mathrm{ppm}$ broad (complex system); $\mathrm{CH}_{2}$ in $\alpha$ to the hydroxy groups of DHE $3.5 \mathrm{ppm} \mathrm{m}$ (complex system).

The ${ }^{1} \mathrm{H}$ NMR $\left(\mathrm{D}_{2} \mathrm{O}\right)$ spectrum of ISA23 was as follows: $\mathrm{CH}_{2}$ in $\alpha$ and $\beta$ to the amidic group of BAC 3.0-3.2 ppm m (complex system); $\mathrm{CH}$ in $\alpha$ to the amidic group of BAC $5.6 \mathrm{ppm} \mathrm{s} ; \mathrm{CH}_{3}$ of 2-MePip $1.3 \mathrm{ppm} \mathrm{d} ; \mathrm{CH}_{2}$ of 2-MePip 3.1-3.8 ppm m (complex system).

The NMR spectra of the random and block copolymers were superimposable compared to the ISA 1 and ISA 23 spectra. The composition of the copolymers was determined by measuring the ratio of $\mathrm{CH}$ in $\alpha$ to the amidic group of BAC (5.6 ppm s), and $\mathrm{CH}_{3}$ of 2-MePip (1.3 ppm d). The values found had a good correlation with the composition of the monomer feed, within the experimental error $( \pm 5 \%)^{\mathrm{a}}$

\section{Evaluation of PAA Cytotoxicity Using B16F10 Cells}

B16F10 cells were cultured in RPMI-1640 supplemented with $10 \%(\mathrm{v} / \mathrm{v})$ heat inactivated FBS and maintained

\footnotetext{
a All NMR spectra show many overlapping signals in the range 2.8-4.0 ppm (for the ${ }^{1} \mathrm{H}$ spectra) and between 40-60 ppm (for the ${ }^{13} \mathrm{C}$ spectra), due to different dimethylene groups with similar chemical shifts. In addition, the signals were broad because of the coupling of nuclear spins. This is not unexpected. In NMR spectra of small molecules, these interactions are averaged to zero by rapid, isotropic tumbling. However, in polymer solutions, the molecular motion is slow enough that this coupling can contribute significantly to the spectrum. ${ }^{[20]}$
} 
at $37^{\circ} \mathrm{C}$ in a humid incubator with a $5 \%$ (v/v) $\mathrm{CO}_{2}$ atmosphere. No antibiotics were added. The cells were subcultured every $4 \mathrm{~d}$ at a split ratio of 1:10. Polymer cytotoxicity was assessed during the log phase of cell growth using an MTT assay as described previously. ${ }^{[17]}$ Cells were added to 96 -well microtitre plates at a density of $1 \times 10^{4}$ cells/well $24 \mathrm{~h}$ prior to the assay. Polymer solutions $(0.2 \mu \mathrm{m}$ filtered) were made in complete RPMI1640 medium to give a concentration range of 0 to $2 \mathrm{mg} / \mathrm{ml}$. At the start of the experiment the culture medium was removed and the desired polymer solution was added $(100 \mu \mathrm{l})$. After $67 \mathrm{~h}$ MTT $(20 \mu \mathrm{l} ; 5 \mathrm{mg} / \mathrm{ml}$ in PBS sterile filtered) was added to each well and the plates re-incubated for a further $5 \mathrm{~h}$. The formazan crystals were dissolved in DMSO and concentration read at $550 \mathrm{~nm}$ using a microtitre plate reader. Cells grown in media alone were used as a reference for $100 \%$ viability. The results were expressed as viability (\%) relative to a control containing no polymer.

\section{Evaluation of PAA-Mediated Gelonin Delivery}

A method previously described ${ }^{[14]}$ was used to assess the ability of the PAAs to deliver gelonin. ${ }^{[21]} \mathrm{B} 16 \mathrm{~F} 10$ cells were plated as described above. PAAs, at concentrations from 0 to $2 \mathrm{mg} / \mathrm{ml}$, where then added to cells in the presence or absence of gelonin $(0.2 \mu \mathrm{m}$ filtered; $1.4 \mu \mathrm{g} / \mathrm{ml})$ and cytotoxicity was determined after $72 \mathrm{~h}$ by MTT assay as described above.

\section{Evaluation of PAA-Induced Haemolysis}

The haemolytic activity of the PAAs was evaluated using a rat red blood cell lysis assay as previously described. ${ }^{[22]} \mathrm{A}$ male Wistar rat was killed by $4 \% \mathrm{CO}_{2}$ asphyxiation. Blood was obtained by cardiac puncture and collected in a heparin blood tube. The tube was centrifuged at $1000 \times \mathrm{g}$ for $10 \mathrm{~min}$ at $4{ }^{\circ} \mathrm{C}$, the plasma was discarded and the erythrocytes (RBC), collected in the pellet, were re-suspended in prechilled PBS and re-centrifuged twice, as described above. The final pellet was re-suspended in pre-chilled PBS at $\mathrm{pH} 5.5,6.5$ and 7.4, in order to give a $2 \%(\mathrm{w} / \mathrm{v}) \mathrm{RBC}$ suspension. Fresh solutions of each polymer $(2 \mathrm{mg} / \mathrm{ml})$ were prepared in PBS at a starting $\mathrm{pH}$ of 5.5, 6.5 and 7.4. These solutions $(100 \mu \mathrm{l})$ were added to 96 -well plates and the appropriate RBC suspension was added at a 1:1 (v/v) ratio. The plates were incubated for $1 \mathrm{~h}$ at $37^{\circ} \mathrm{C}$. After this time the plate was centrifuged at $1000 \times \mathrm{g}$ for $10 \mathrm{~min}$ at room temperature. The haemoglobin $(\mathrm{Hb})$ content of the supernatant was measured spectrophotometrically at $550 \mathrm{~nm}$ using a microtiter plate reader. Haemolysis was expressed as a percentage of the value obtained using Triton X-100 (1\% w/v Triton X-100) which was used to provide a $100 \%$ value.

\section{Results and Discussion}

Since 1990 a steady stream of polymer therapeutics, particularly polymer-protein and polymer-drug conjugates, have entered clinical trial, and in some cases the market. ${ }^{[23]}$ However, with the completion of the human genome project, and the recent advances in proteomics, there is an ever increasing need to design nano-vectors able to deliver genes and macromolecular drugs (particularly proteins and peptides) to the cytoplasm of the cell. ${ }^{[24]}$ In nature, viruses deliver their DNA (or RNA) to the cytosol using fusogenic peptides and proteins ${ }^{[25]}$ To overcome the recognised disadvantages of viral vectors, many are investigating synthetic mimetics, ${ }^{[26-29]}$ and much effort has been directed towards the design of $\mathrm{pH}$-responsive endosomolytic polymers that might efficiently open the endosomal membrane, and allow cytosolic access of macromolecular drugs without the need to use a protein or peptide. ${ }^{[30-36]}$

Our past research led us to PAAs. These are watersoluble, cationic polymers that demonstrate endosomolytic properties. ${ }^{[9,13,14]}$ This behaviour has been confirmed using model systems, ${ }^{[13,14]}$ and also isolated lysosomal vesicles containing PAAs. ${ }^{[37]}$ The composition of the ISA 23-ISA 1 random and block copolymers described here was selected with the aim of designing a hybrid polymer with an isoelectric point slightly below 7.4, i.e., a negative net average charge at $\mathrm{pH} 7.4$, but also with a greater positive charge than ISA 23 at acidic $\mathrm{pH}^{\left[{ }^{[9]}\right.}$ The net average charge of PAAs and their isoelectric points, can be calculated from their monomer composition. ${ }^{[9]}$ In this case, theoretical calculations suggested that the charge density, and total charge, of ISA 23:ISA 1 copolymer compositions with a molar ratio in the range $2: 1-4: 1$ would fulfil the above aim (Figure 2). The net average charge will be the same for block and random copolymers of the same composition.

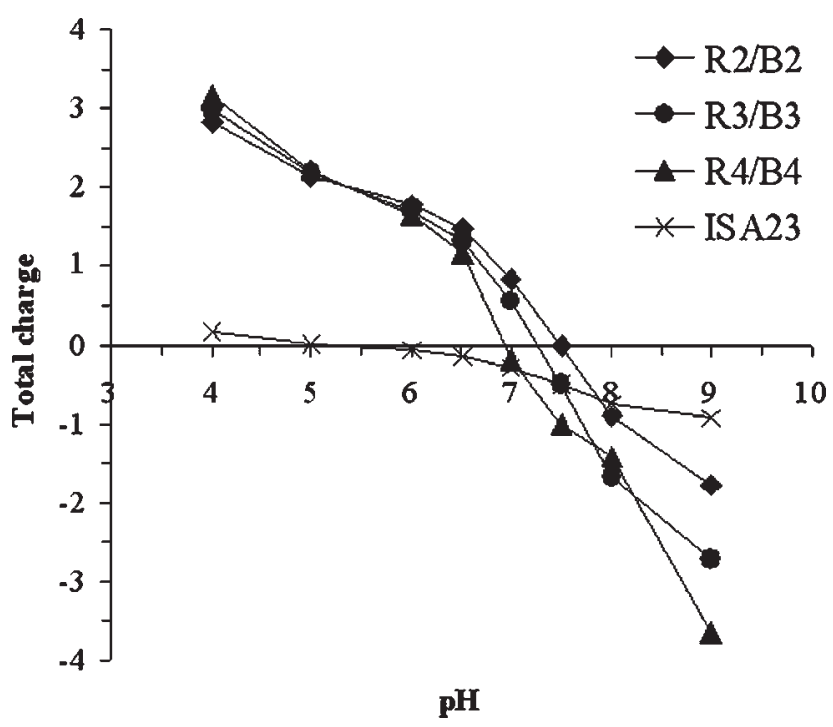

Figure 2. Influence of the $\mathrm{pH}$ on the total charge of amphiphile poly(amidoamine)s. 
However, the charge distribution along the polymer chain will be quite different. Positive and negative charge is expected to be evenly distributed in random copolymers, but will be grouped within ISA 23 amphoteric sequences in the block copolymers. In fact, at physiological pH the block copolymers will have sequences of purely positive charges (ISA 1) combined with amphoteric sequences of negative and positive charge (ISA 23), with a prevalence of anionic character. Furthermore, each PAAs repeating units can be considered as separate molecules and though will behave nearly independently towards protonation. ${ }^{[1-3]}$ Hence, the complex molecular architecture of the copolymers should induce no or little variation of the aminic nitrogen pKa values relative to the parent polymer ISA1 and ISA23 (Figure 1).

The random copolymers (Table 1) were prepared (Scheme 1) simply by mixed polyaddition of BAC, BP, 2MePip and DHE, in the appropriate ratios. Based on previous experience, no sequentially ordered PAA copolymers may be expected if all the co-monomers are mixed together before starting polymerisation. The block copolymers (Table 1) were synthesised (Scheme 2) starting from ISA 23 and ISA 1 pre-polymers amino-terminated at both ends. The polymerisation degree of these pre-polymers was planned to be 19 according to the well known relation between the limit number-average polymerisation degree and the initial stoichiometric ratio $r$ of the monomers ${ }^{[38]}$ (Equation 1):

$$
\overline{X_{n}}=\frac{1+r}{1-r}
$$

NMR has shown ${ }^{[39]}$ that when bis-secondary amines are employed as monomers, this relationship is perfectly fulfilled when (as in the present case) the excess is an amine function. However, the relationship does not always hold true when an excess bisacrylamide is used. ${ }^{[3]}$ This makes it difficult to predict the polymerisation degree of a vinyl-terminated pre-polymer. The $\alpha, \omega$-bisamino terminated ISA 1 and ISA 23 pre-polymers were used for the

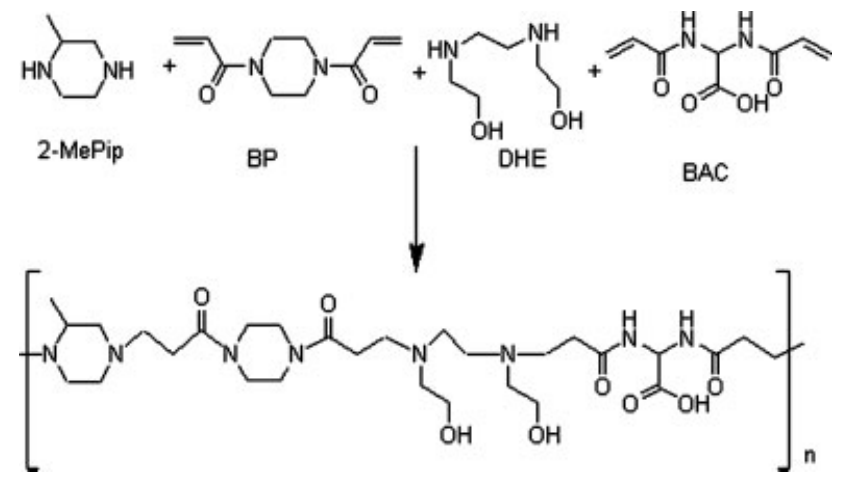

Scheme 1. Synthesis of random copolymers of ISA 23 and ISA 1.

subsequent chain-extension step without isolation, using the same bisacrylamides used for the preparation of ISA 1 and ISA 23. The total number of double bonds equalled, in all cases, the number of amino groups. For this reason, the procedure described here was preferred to preparation and direct coupling of complementary pre-polymers, that is, $\alpha, \omega$-terminated with amino groups and double bonds respectively.

The $\bar{M}_{\mathrm{w}}$ of the random copolymers varied between 19000 and $43000 \mathrm{~g} / \mathrm{mol}$ (Table 1) and these polymers had a polydispersity index of $<2$. The block copolymers had a higher $\bar{M}_{\mathrm{w}}$, in the range 35000 to $50000 \mathrm{~g} / \mathrm{mol}$, and a polydispersity index of up to 2.7 (Table 1 ). Their $\bar{M}_{\mathrm{w}}$ corresponds to approximately 6 blocks (three for each type) per macromolecule. The composition of the copolymers was determined from their ${ }^{1} \mathrm{H}$ NMR spectra, by measuring the ratio between the peak at $5.6 \mathrm{ppm}$ (corresponding to NCHN group of the BAC monomer) and the peak at $1.3 \mathrm{ppm}$, (corresponding to $\mathrm{CH}_{3}$ group of the 2-MePip monomer). It was found to correlate well with that of the monomer feed ratio (Data not shown). This was expected as when the polymerisation is brought to high yields the copolymer composition reflects the stoichiometry of the monomer feed. ${ }^{[40]}$

Table 1. Chemical characteristics of the random (R2, R3, R4) and block (B2, B3, B4) copolymers.

\begin{tabular}{lccccc}
\hline Polymer & ISA 23:ISA 1 Molar ratio & $\bar{M}_{\mathrm{w}}{ }^{\mathrm{a})}$ & $\bar{M}_{\mathrm{n}}{ }^{\mathrm{a}}$ & $\bar{M}_{\mathrm{w}} / \bar{M}_{\mathrm{n}}{ }^{\text {a) }}$ & $\mathrm{pI}^{\mathrm{b})}$ \\
\hline ISA1 & - & 12300 & 6900 & 1.78 & - \\
ISA23 & - & 50826 & 28469 & 1.78 & 5.5 \\
Random copolymers & $2: 1$ & 19900 & 13100 & 1.52 & 7.5 \\
R2 & $3: 1$ & 43000 & 24100 & 1.78 & 7.3 \\
R3 & $4: 1$ & 23200 & 16000 & 1.45 & 6.9 \\
R4 & & & & & 7.5 \\
Block copolymers & $2: 1$ & 35200 & 14700 & 2.39 & 7.3 \\
B2 & $3: 1$ & 49000 & 18200 & 2.69 & 6.9 \\
B3 & $4: 1$ & 45700 & 18700 & 2.44 & \\
B4 & & & &
\end{tabular}

a) The $\bar{M}_{\mathrm{w}}, \bar{M}_{\mathrm{n}}(\mathrm{g} / \mathrm{mol})$ and $\bar{M}_{\mathrm{w}} / \bar{M}_{\mathrm{n}}$ were calculated by GPC using PVP standards as described in the text.

b) $\mathrm{pI}$ was calculated. 


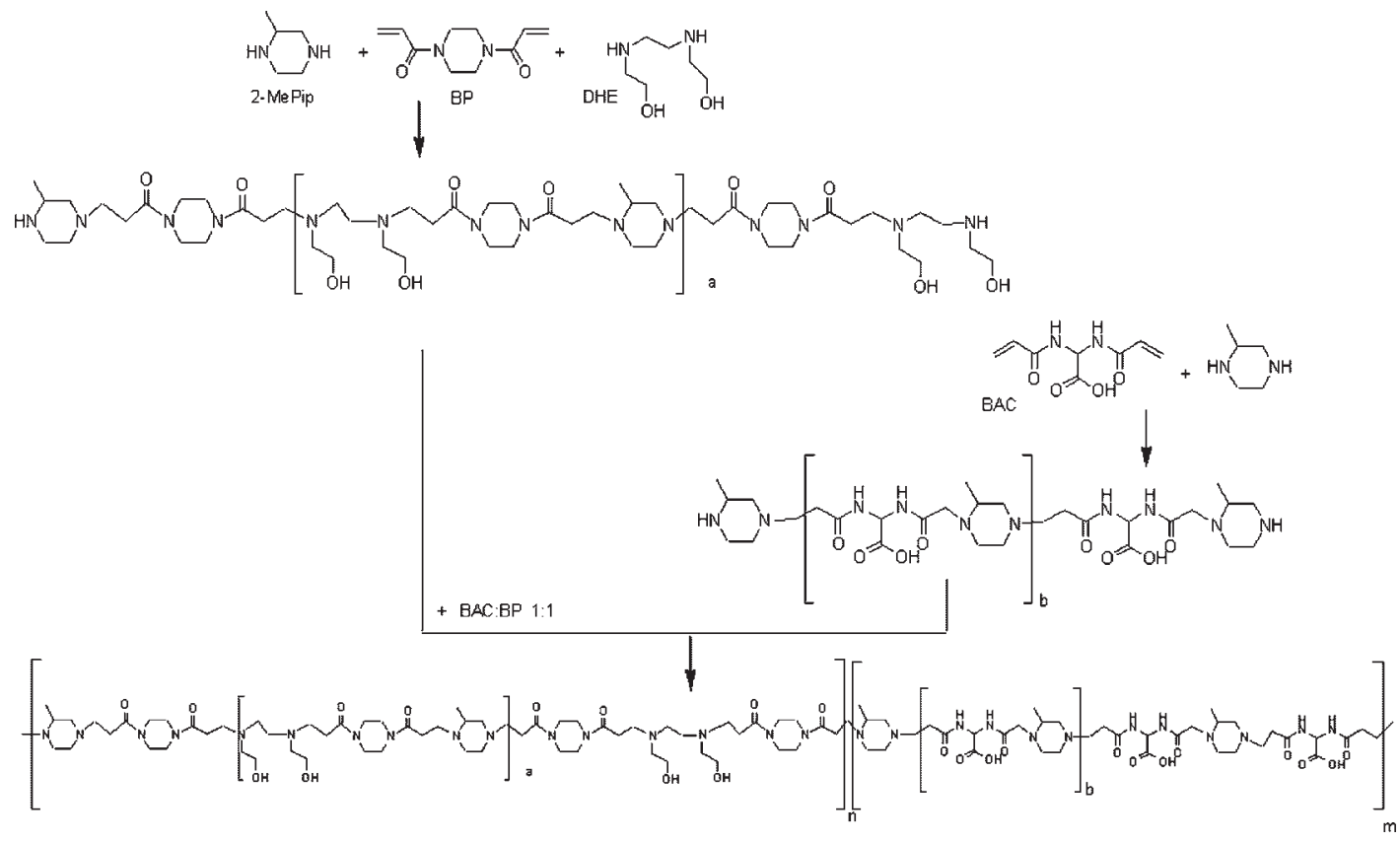

Scheme 2. Synthesis of block copolymers of ISA 23 and ISA 1.

It was first important to determine whether synthesis of such random and block copolymers would increase PAA general cytotoxicity, thus making them unsuitable for in vivo administration. Following incubation of the hybrid PAAs with B16F10 cells for $72 \mathrm{~h}$, all were found less toxic compare to the parent ISA 1 . The $\mathrm{IC}_{50}$ values observed were all $>2 \mathrm{mg} / \mathrm{ml}$ and $1.5 \mathrm{mg} / \mathrm{ml}$ (Figure 3). Second, it was hoped that these random and block copolymers would still demonstrate $\mathrm{pH}$ dependent membrane permeability.
When the ISA 23-ISA 1 block and random copolymer hybrids were tested for their haemolytic activity at physiological $(\mathrm{pH}=7.4)$, endosomal $(\mathrm{pH}=6.5)$ and lysosomal $(\mathrm{pH}=5.5) \mathrm{pH}$, all polymers displayed haemolytic activity which was not distinguishable from the PBS and dextran controls (10\% Hb release) at $\mathrm{pH} 7.4$ (Figure 4). At pH 6.5 a two-fold increase in haemolysis was generally observed for each PAA hybrid, whereas at $\mathrm{pH} 5.5$ the $\mathrm{Hb}$ release showed a 5-fold increase compared to $\mathrm{pH} 7.4$ (50 to $60 \% \mathrm{Hb}$

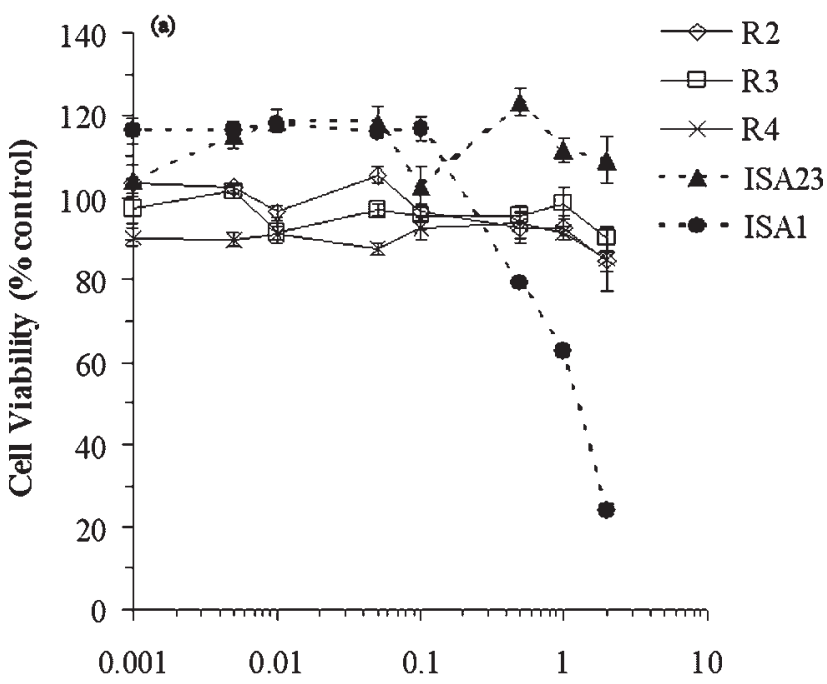

Polymer Concentration (mg/m)

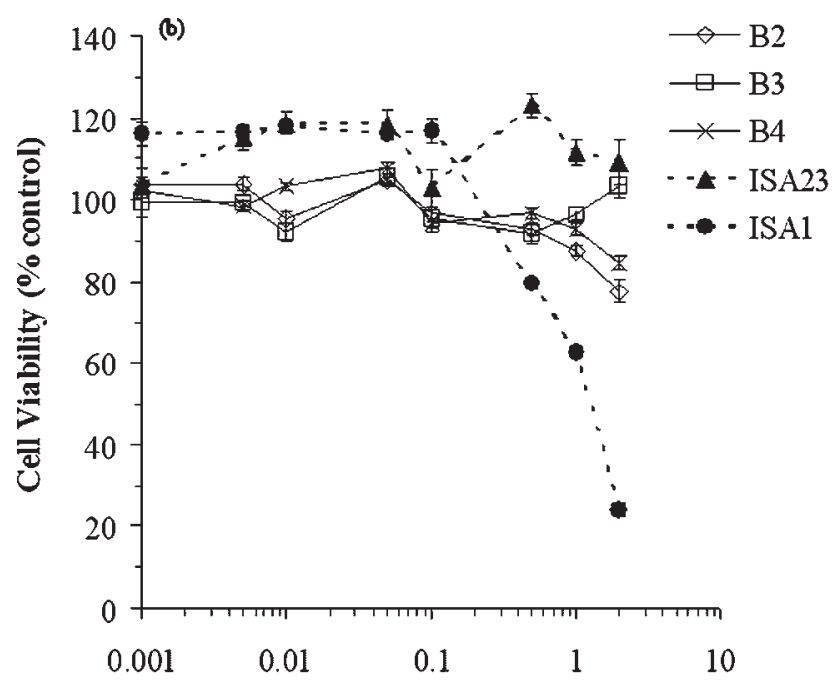

Polymer Concentration (mg/ml)

Figure 3. PAA cytotoxicity towards B16F10 mouse melanoma. Panel (a) shows the relative toxicity of random copolymers (R2, R3, R4) and the parent polymers ISA 23 and ISA 1 . Panel (b) shows the relative toxicity of block copolymers (B2, B3, B4) and the parent polymers ISA 23 and ISA 1 . Viability is expressed as $\%$ of the growth of control cells incubated in medium alone. Data represent mean \pm SEM $(n=12)$. 


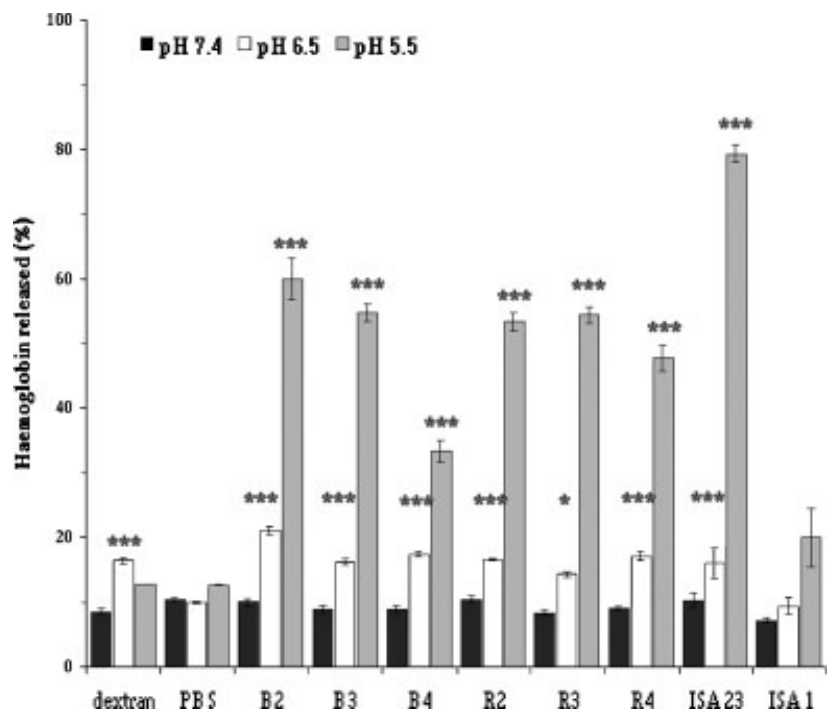

Figure 4. pH-Dependent haemolytic activity of random and block copolymers $(1 \mathrm{mg} / \mathrm{ml})$ after $1 \mathrm{~h}$ incubation at $37^{\circ} \mathrm{C}$. $\mathrm{Hb}$ release is expressed as \% of the value obtained by Triton X-100 $(1 \%(\mathrm{w} / \mathrm{v})-100 \%$ lysis $)$. Data represent mean $\pm \operatorname{SEM}(n=6)$. Data analysis was done using 1 way ANOVA followed by Bonferroni test $(\alpha=0.01)$. For each $\mathrm{pH}$, haemolysis was compared to the control (PBS): $* * * p<0.001 ; * p<0.05$.

release). Under the same conditions, the parent polymers ISA 1 and ISA 23 were also not haemolytic at $\mathrm{pH} 7.4$ and 6.5 , but at $\mathrm{pH} 5.5$ showed $20 \%$ and $80 \%$ haemolysis activity, respectively. Although these observations indicate a $20-30 \%$ reduction in membrane activity of the hybrids, compared to ISA 23, they demonstrated a 30-40\% increase compared to ISA 1.

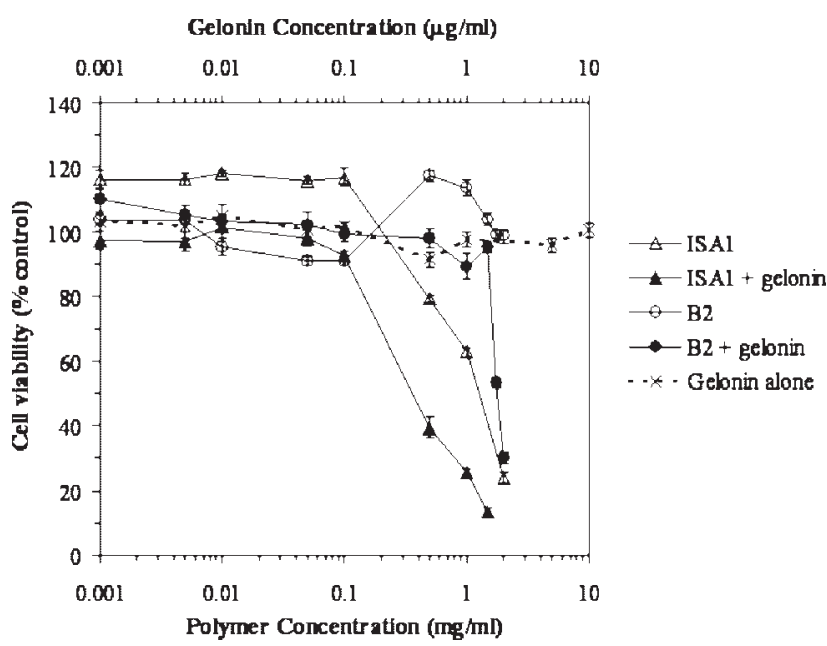

Figure 5. Cytotoxicity of gelonin and ability of the block copolymer B2 to promote cytotoxicity of the toxin to B16F10 cells. Cells were incubated at $37^{\circ} \mathrm{C}$ for $72 \mathrm{~h}$ with gelonin alone or PAAs with or without a non-toxic concentration of gelonin $(1.4 \mu \mathrm{g} / \mathrm{ml})$. Viability was determined using an MTT assay and is expressed as \% of the growth of control cells incubated in medium alone. Data represent mean $\pm \operatorname{SEM}(n=12)$.
Gelonin $\left(\bar{M}_{\mathrm{w}}=30 \mathrm{kDa}, \mathrm{pI}=8.15\right)$, a ribosome inactivating protein, lacks a cell binding domain and is a nonpermeant toxin. ${ }^{[41]}$ Gelonin alone is not toxic to intact cells due to its poor uptake and its trafficking to the lysosomes where it is degraded by enzymes. ${ }^{[21]}$ ISA 1 has been shown to promote intracytoplasmic delivery of gelonin and ricin A chain ${ }^{[14]}$ in B16F10 cells and also other cell lines. ${ }^{[42]}$ ISA23 has consistently failed to do this, ${ }^{[14]}$ although it is able to deliver DNA. ${ }^{[13]}$ It was hoped that combination of the consistent monomers as a random or block copolymer, would result in hybrid structures that would enable intracytoplasmic delivery of toxins. Of this series reported here the block copolymer B2 (ISA 23:ISA 1 2:1) did have the ability to deliver gelonin (Figure 5). At higher polymer concentration, a marked decrease in B16F10 viability can be seen when the cells are incubated with a combination of gelonin, in the presence of the B2 block copolymer $\left(\mathrm{IC}_{50}=1.8 \mathrm{mg} / \mathrm{ml}\right)$. Neither $\mathrm{B} 2$ alone nor gelonin $\left(\mathrm{IC}_{50}>10 \mu \mathrm{g} / \mathrm{ml}\right)$ display any cytotoxicity and moreover none of the other random and block copolymers were able to promote cytoplasmic delivery of gelonin. This is interesting as it suggests a narrow tolerance in terms of PAAs composition for optimal gelonin delivery.

\section{Conclusion}

ISA 1 and ISA 23 random and block copolymers can be synthesised to have a $\bar{M}_{\mathrm{w}}$ in the range $13000-50000 \mathrm{~g} / \mathrm{mol}$ and were non toxic against B16F10 cells $\left(\mathrm{IC}_{50}>2.0 \mathrm{mg} /\right.$ $\mathrm{ml}$ ). Although all the hybrid PAA copolymers demonstrated preserved $\mathrm{pH}$-dependent membrane perturbation, manifest as haemolytic activity, only the ISA 23:ISA 1 (2:1) block copolymer showed ability to promote cytoplasmic delivery of gelonin. It would be interesting to study the mechanism of action of this polymer further and undertake pharmacokinetic studies to see if such a block copolymer might also display "stealth" properties.

In general, the synthesis of random, block and graft copolymers designed as improved endosomolytic polymers suitable for in vivo (and later clinical) use have displayed disappointing properties in terms of improved membrane destabilisation at endosomal $\mathrm{pH}$. Thus, we are currently trying to define more clearly the solution properties of PAAs at intracellular $\mathrm{pH}^{[11,12]}$ and their mechanisms of membrane destabilisation. ${ }^{[43]}$ Only with this information will it become possible to tailor the most effective hybrid structures.

Acknowledgements: We would like to thank BBSRC for supporting this work.

[1] P. Ferruti, M. Marchisio, R. Barbucci, Polymer 1985, 26, 1336. 
[2] P. Ferruti "Polymeric Materials Encyclopedia", J. C. Salamone, Ed., CRC Press, Boca Raton 1996, p. 3334.

[3] P. Ferruti, M. Marchisio, R. Duncan, Macromol. Chem. Phys. 2002, 23, 332.

[4] E. Ranucci, G. Spagnoli, P. Ferruti, D. Sgouras, R. Duncan, J. Biomater. Sci., Polym. Ed. 1991, 2, 303.

[5] P. Ferruti, R. Duncan, S. Richardson, "Targeting of Drugs 6. Strategies for Stealth Therapeutics Systems", G. Gregoriadis, B. Mc Cormack, Eds., Plenum Press, New York 1998, p. 207.

[6] G. Wu, C. Wu, J. Biol. Chem. 1987, 262, 4429.

[7] O. Boussif, F. Lezoualch, M. Zanta, M. Mergny, D. Scherman, B. Demeneix, J. P. Behr, Proc. Natl. Acad. Sci. USA 1995, 92, 7297.

[8] J. D. Eichman, A. U. Bielinska, J. F. Kukowska-Latallo, J. R. Baker, Pharm. Sci. Technol. Today 2000, 3, 232.

[9] P. Ferruti, S. Manzoni, S. C. W. Richardson, R. Duncan, N. G. Pattrick, R. Mendichi, M. Casolaro, Macromolecules 2000, 33, 7793.

[10] S. C. W. Richardson, P. Ferruti, R. Duncan. J. Drug Targeting 1999, 6, 391.

[11] K.-W. Wan, B. Malgesini, I. Verpilio, P. Ferruti, P. C. Griffiths, A. Paul, A. C. Hann, R. Duncan, Biomacromolecules 2004, 5, 1102.

[12] P. C. Griffiths, A. Paul, Z. Khayat, K. W. Wan, S. M. King, I. Grillo, R. Schweins, P. Ferruti, J. Franchini, R. Duncan, Biomacromolecules 2004, 5, 1422.

[13] S. C. W. Richardson, N. G. Pattrick, Y. K. S. Man, P. Ferruti, R. Duncan, Biomacromolecules 2001, 2, 1023.

[14] N. G. Pattrick, S. C. W. Richardson, M. Casolaro, P. Ferruti, R. Duncan, J. Controlled Release 2001, 77, 225.

[15] H. Maeda, Y. Matsumura, Crit. Rev. Ther. Drug Carrier Syst. 1989, 6, 193.

[16] B. Malgesini, I. Verpilio, R. Duncan, P. Ferruti, Proc. $6^{\text {th }}$ Int. Symp. Polymer Therapeutics 2003, 86.

[17] D. Sgouras, R. Duncan, J. Mater. Sci. Mater. Med 1990, 1, 61.

[18] P. Ferruti, E. Ranucci, F. Trotta, E. Gianasi, G. E. Evagorou, M. Wasil, G. Wilson, R. Duncan, Macromol. Chem. Phys. 1999, 200, 1644.

[19] P. Ferruti. Macromol. Syntheses 1985, 9, 25.

[20] A. J. Brandolini, D. D. Hills, "NMR spectra of Polymers and Polymer Additives", Marcel Dekker Inc., New York 2000.

[21] F. Stirpe, S. Olsnes, A. Pihl, J. Bio. Chem. 1980, 255, 6947.
[22] B. Carreno-Gomez, R. Duncan, Int. J. Pharm. 1997, 148, 231.

[23] R. Duncan, Nature Reviews Drug Discovery 2003, 2, 347.

[24] E. Wagner, Pharm. Res. 2004, 21, 8 .

[25] W. Li, F. Nicol, F. C. Szoka, Adv. Drug Delivery Rev. 2004, 56, 967.

[26] S. P. Chamarthy, J. R. Kovacs, E. McClelland, D. Gattens, W. S. Meng, Mol. Immunol. 2003, 40, 483.

[27] H. Lee, J. H. Jeong, T. G. Park, J. Controlled Release 2002 , 79, 283.

[28] E. Wagner, Adv. Drug Del. Rev. 1999, 38, 279.

[29] D. M. Lynn, M. M. Amiji, R. Langer, Angew. Chem. Int. Ed. 2001, 40, 1707.

[30] T. M. Reineke, M. E. Davis, Bioconjugate Chem. 2003, 14, 247.

[31] M. Ogris, G. Walker, T. Blessing, R. Kircheis, M. Wolschek, E. Wagner, J. Controlled Release 2003, 91, 173 .

[32] C. L. Gebhart, S. Sriadibhatla, S. Vinogradov, P. Lemieux, V. Alakhov, A. V. Kabanov, Bioconjugate Chem. 2002, 13, 937

[33] V. Bulmus, M. Woodward, L. Lin, N. Murthy, P. S. Stayton, A. S. Hoffman, J. Controlled Release 2003, 93, 105.

[34] T. R. Kyriakides, C. Y. Cheung, N. Murthy, P. Bornstein, P. S. Stayton, A. S. Hoffman, J. Controlled Release 2002, 78, 295.

[35] D. Putnam, A. N. Zelikin, V. A. Izumrudov, R. Langer, Biomaterials 2003, 24, 4425 .

[36] A. M. Funhoff, C. F. van Nostrum, G. A. Koning, N. M. E. Schurmans-Nieuwenbroek, D. J. A. Crommelin, W. E. Hennink, Biomacromolecules 2004, 5, 32.

[37] N. G. Pattrick, P. Ferruti, R. Duncan, Proc. Int. Symp. Control. Rel. Bioactive Mater. 2001, 28, 864.

[38] P. J. Flory, "Principles of polymer chemistry", Cornell University Press, London 1953.

[39] F. Bignotti, P. Sozzani, E. Ranucci, P. Ferruti, Macromolecules 1994, 27, 7171.

[40] P. Ferruti, F. Danusso, G. Franchi, N. Polentarutti, S. Garattini, J. Medicinal Chem. 1973, 16, 497.

[41] A. Falaska, A. Gasperi-Campani, A. Abbondanza, L. Barbieri, F. Stirpe, Biochem. J. 1982, 207, 505.

[42] K.-W. Wan, M. O'Brien, R. Duncan, Proc. $6^{\text {th }}$ Int. Symp. Polymer Therapeutics 2004, 95.

[43] P. C. Griffiths, A. Paul, Z. Khayat, K. Millership, K. W. Wan, R. Duncan, Proc. $6^{\text {th }}$ Int. Symp. Polymer Therapeutics 2004, 4. 